\title{
DESENVOLVIMENTO DE MATERIAL DIDÁTICO ADAPTADO PARA CRIANÇAS COM DEFICIÊNCIA VISUAL NO ENSINO DA GEOMETRIA
}

\section{DEVELOPMENT OF DIDACTIC MATERIALADAPTED FOR CHILDREN WITH VISUAL IMPAIRMENT IN THE TEACHING OF GEOMETRY}

\author{
Fernanda Domingues ${ }^{1}$, Mestranda \\ Laís Cristina Licheski², Dra. \\ (1) Universidade Federal do Paraná \\ e-mail: Fernanda.fdomingues@gmail.com \\ (2) Universidade Tecnológica Federal do Paraná \\ e-mail: laislic@utfpr.edu.br
}

Material didático adaptado, deficiência visual, geometria

Este artigo apresenta um estudo que projetou material didático adaptado para crianças com deficiência visual da primeira série do ensino fundamental, constituído por formas geométricas para o auxílio no ensino da Matemática. $\mathrm{O}$ foco foi a aprendizagem multissensorial, buscando se projetar sem perder de foco a viabilização do projeto nas escolas. A pesquisa realizou-se em duas fases: teórica e prática. Na primeira, foi realizada revisão de literatura para obtenção de dados sobre deficiência visual, processos de inserção e aprendizagem nas escolas e recursos educacionais empregados. A segunda parte constituiu-se em pesquisa de campo, execução do modelo e testagem. Foram realizadas entrevistas com educadores e alunos, além testes com o público-alvo, processo fundamental para a compreensão e elaboração do protótipo. Os principais pontos abordados e considerados pelos alunos foram o emprego do Braille em alta consistência para se indicar o nome das peças geométricas e a utilização de cores saturadas.

\section{Adapted didactic material, visual impairment, geometry}

This article presents a study that designed didactic material adapted for children with visual impairment of the first grade of elementary school, constituted by geometric forms to aid in the teaching of Mathematics. The focus was on multi-sensory learning, seeking to project without losing sight of the viability of the project in schools. The research was carried out in two phases: theoretical and practical. In the first, a literature review was performed to obtain data on visual impairment, insertion and learning processes in schools and educational resources employed. The second part consisted of field research, model execution and testing. Interviews were conducted with educators and students, as well as tests with the target audience, a fundamental process for understanding and elaborating the prototype. The main points considered and considered by the students were the use of Braille in high consistency to indicate the name of the geometric pieces and the use of saturated colors. 


\section{$16^{\circ}$ \\ ERGODESIGN USIHC CINAHPA}

\section{Introdução}

Segundo Adam (2011), o Brasil é um país reconhecido pela escassez de recursos didáticos para crianças com deficiência visual em fase de alfabetização. Existem cerca de 169 mil pessoas com deficiência visual, destes apenas $10 \%$ alfabetizados em Braille, como cita Oliveira (2011). Considerando tais estatísticas, Gomes (2008) atenta que a falta de investimento e desenvolvimento na área culminou em um mercado extremamente carente, que necessita de novas iniciativas e modelos. Inclusos tanto em escolas de ensino regular quanto de ensino especial, Lopes (2013) destaca que os estudantes com deficiência visual necessitam de métodos de aprendizagem que fogem aos padrões já utilizados, tendo a interação e a tecnologia como principais aliadas no processo de ensino. Nesse contexto, chama-se a atenção para o grande potencial do design nas soluções que podem ser criadas a partir de estudos gráficos e de interação mais abrangentes.

Este artigo apresenta o projeto de desenvolvimento de material didático adaptado para constituído por formas geométricas para o auxílio no ensino da Matemática, visando principalmente a inclusão de pessoas com deficiência visual através da interação e aprendizagem multissensorial. Para tal, foi necessário observar-se a inserção de crianças com deficiência visual nas escolas e os materiais gráficos disponibilizados a cegos e alunos com baixa visão matriculados na rede pública de ensino de Curitiba-Pr. Materiais didáticos

complementares são de extrema importância tanto em escolas exclusivas a pessoas com deficiência visual quanto em escolas regulares, nas quais os alunos com baixa ou nenhuma visão estejam imersos em um contexto vidente. Nas últimas, poucos professores possuem a devida formação para educar esse tipo de aluno, sendo o material didático adaptado um dos protagonista da aprendizagem em alguns contextos, como considera Pereira (2013). $16^{\circ}$ Ergodesign - Congresso Internacional de Ergonomia e Usabilidade de Interfaces Humano Tecnológica: Produto, Informações Ambientes Construídos e Transporte

$16^{\circ}$ USIHC - Congresso Internacional de Ergonomia e Usabilidade de Interfaces Humano Computador

CINAHPA | 2017 - Congresso Internacional de Ambientes Hipermídia para Aprendizagem.

\section{Procedimentos metodológicos}

Este estudo teve caráter qualitativo, que segundo Flick (2009), forma-se por um sistema de técnicas principalmente interpretativas, que vêm com o objetivo de decifrar uma rede de problemas e significados. A pesquisa realizou-se em duas fases: teórica e prática. Na teórica, foi realizada revisão de literatura, já a prática constitui-se por pesquisa de campo, execução do modelo e testagem. Fundamental para o desenvolvimento da pesquisa, além da coleta de dados acerca da deficiência visual e do processo de inserção das crianças nas escolas regulares, a revisão de literatura trouxe os estudos de Azevedo (2012), que em sua dissertação de mestrado pela Universidade Federal do Rio de Janeiro, apresentou estudo sobre a utilização de material adaptado magnético no ensino da Física. Na segunda etapa, entre entrevistas e execução do protótipo, realizou-se também curso de Braille ofertado gratuitamente pela Biblioteca Pública do Paraná. Nas aulas, toda a escrita é realizada manualmente, e por meio de sua utilização foi possível testar e compreender todas as dificuldades que a envolvem. Aprender o sistema foi indispensável também para a execução das peças geométricas. Por último, os testes com os alunos foram de suma importância para se compreender como o artefato seria utilizado, suas falhas e pontos positivos para o processo de aprendizagem.

\section{Fundamentação teórica}

\subsection{Deficiência visual e deficiência visual infantil no Brasil}

A expressão "Deficiência Visual", de acordo com Gil (2000), é referente ao espectro que vai da cegueira até a visão subnormal ou baixa visão. Seguindo critérios pedagógicos, define-se como cego aquele que, mesmo possuindo baixa visão ou visão subnormal, necessita de instruções em Braille, como cita Souza et al (2005). Este estudo pretendeu abranger pessoas com deficiência visual que se utilizam do Braille como meio de leitura. Dados da Organização Mundial de Saúde (OMS) compilados pela Sociedade Bíblica do Brasil (2013), apontam que no país há 1,7 milhão de 


\section{$16^{\circ}$ \\ ERGODESIGN USIHC CINAHPA}

pessoas com algum tipo de deficiência visual, ou seja, $1 \%$ da população nacional. Há certa divergência de informações para um diagnóstico específico sobre quais fatores determinam a perda visual especificamente em crianças; segundo Brito et al (2000), as principais causas da cegueira infantil no Brasil, atualmente, são: a hipovitaminose $\mathrm{A}$, a oncocercose, o sarampo e o tracoma.

\subsection{Recursos didáticos adaptados para a criança com deficiência visual}

Segundo Gil (2000), uma criança com deficiência visual necessita ter os outros órgãos do sentido estimulados, de maneira a compensar a privação da mesma de seu canal de apreensão do mundo exterior. Segundo o autor, tendo a criança condições mínimas de comunicação e interação, ela pode e deve ser integrada à pré-escola e a escola comum. A importância do processo préescolar e escolar está principalmente no favorecimento motor, intelectual e emocional do aluno com problemas de visão, além de contribuir para a construção de uma autoimagem positiva e enriquecida constantemente de novos conhecimentos (GIL, 2000). Através da cartilha distribuída pelo Ministério da Educação aos professores de todo o Brasil, tem-se a normativa e instruções no ensino de alunos com baixa visão ou cegos (DIAS e CAMPOS, 2007). Segundo as autoras, existem vários recursos táteis que devem ser empregados na aprendizagem destas crianças: sólidos geométricos e jogos de encaixe, por exemplo, são meios didáticos que podem ser compartilhados com todos os alunos e não precisam passar por nenhum processo de adaptação para tal. Entretanto, as autoras ainda destacam alguns critérios e cuidados devem ser seguidos na criação de materiais e recursos didáticos para pessoas com deficiência visual. São eles: - fidelidade máxima de representação em relação ao modelo original;

- utilização de objetos ou desenhos em tamanho adequado para ressaltar adequadamente suas formas e detalhes; $\mathrm{e}$

- o relevo é um dos melhores recursos e também o mais utilizado, por facilitar a percepção e a $16^{\circ}$ Ergodesign - Congresso Internacional de Ergonomia e Usabilidade de Interfaces Humano Tecnológica: Produto, Informações Ambientes Construídos e Transporte

$16^{\circ}$ USIHC - Congresso Internacional de Ergonomia e Usabilidade de Interfaces Humano Computador

CINAHPA | 2017 - Congresso Internacional de Ambientes Hipermídia para Aprendizagem. distinção pelo tato. Pode-se constituir de diferentes texturas para criar a melhor representação de um todo.

Azevedo (2012, p.3) sugere a utilização de materiais adaptados que sejam de baixo custo e fácil obtenção, ao mesmo tempo que tais recursos estimulem o envolvimento ativo do aluno. Quanto mais o estudante está engajado nas atividades, sua compreensão sobre os temas estudados e reflexão serão melhor fixados e aplicados em seu dia-a-dia. Com base em tais conceitos, o autor, em sua dissertação em física pela UFRJ, realizou pesquisa na qual propôs a utilização de quadros magnéticos como recursos didáticos adaptados, a fim de complementar quaisquer materiais que o professor possa dispor no ensino de alunos com deficiência visual.

A metodologia utilizada baseia-se em princípios principalmente orais, na qual em um primeiro momento o professor faz uma revisão oral da teoria com os alunos para depois montar os gráficos e/ou as figuras no quadro magnético. $\mathrm{O}$ aluno, após a explicação e primeiro contato com o material magnético, deverá refazer, sob supervisão do professor, o conteúdo anteriormente explicitado [AZEVEDO, 2012]. Tal experimentação utilizada por Azevedo (2012, p.5), aplicou-se principalmente durante o estudo de gráficos $\mathrm{e}$ diagramas que ocorrem principalmente nas disciplinas de Física e Matemática. O autor indica a utilização de quadros de aço, medindo 800x500 $\mathrm{mm}$, com ímãs podendo ser feitos manualmente em formas de tiras ou em pequenos cilindros. No desenvolvimento de sua pesquisa, Azevedo (2012, p.10) utiliza o material magnético de forma a facilitar o acesso e compreensão dos alunos no estudo de raios, fazendo com que a aprendizagem seja reforçada a partir do momento em que o estudante com deficiência visual se vê obrigado a montar, como em um quebra-cabeça, o que foi anteriormente explicado pelo educador. A utilização desse material facilita a compreensão, através do tato, do que é uma linha reta, uma descrição abstrata ou uma linha matemática. $\mathrm{Na}$ imagem a seguir, tem-se um estudante fazendo uso de tal recurso no aprendizado de óptica geométrica e luz. 


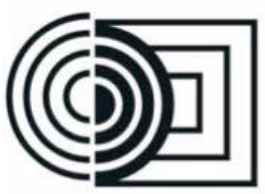

$16^{\circ}$ Ergodesign - Congresso Internacional de Ergonomia e Usabilidade de Interfaces Humano Tecnológica: Produto, Informações Ambientes Construídos e Transporte

$16^{\circ}$ USIHC - Congresso Internacional de Ergonomia e Usabilidade de Interfaces Humano Computador

CINAHPA | 2017 - Congresso Internacional de Ambientes Hipermídia para Aprendizagem.

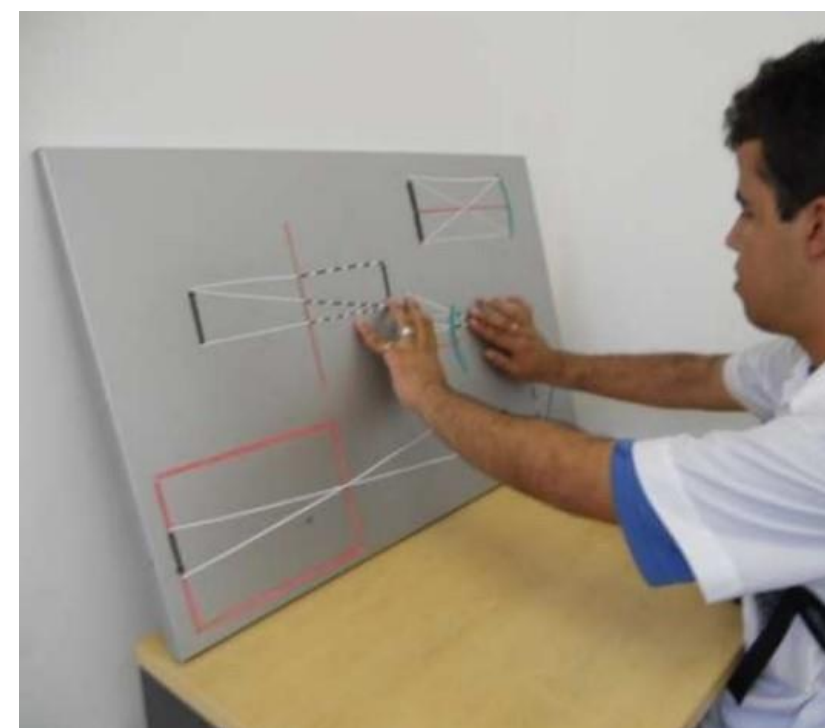

Figura 01: Aluno com deficiência visual fazendo uso do material magnético

Fonte: Azevedo, 2012

Azevedo (2012) conclui sua pesquisa com certo sucesso e aprovação dos alunos que fizeram uso de tal material. Segundo os educadores consultados pelo autor, a placa imantada teve bons resultados na sua utilização principalmente em questões de custos, durabilidade e aceitação dos estudantes.

\section{Desenvolvimento}

A partir da fundamentação teórica realizada, foi necessária a ambientação com o conteúdo desenvolvido para uma melhor aplicabilidade sobre o projeto. Além do curso de Braille anteriormente citado, foram realizadas entrevistas com três educadores da área, dois deles com deficiência visual, afim de se coletar dados sobre o processo de aprendizagem nos primeiros anos escolares. Todos frisaram a importância de materiais além do conteúdo escrito em Braille para um melhor processo de compreensão do mundo exterior. Esses materiais de apoio, além de auxiliarem na construção do conhecimento através de um processo coletivo e construtivo, apresentam caráter lúdico, fundamental considerando-se o público-alvo constituído por crianças entre 4 e 7 anos.

Para a elaboração do protótipo, utilizou-se como base o livro "Marcha Criança - Matemática $1^{\circ}$ ano (2012)", publicado pela editora Scipione. A escolha do exemplar deu-se principalmente pela necessidade de se empregar conteúdos atuais no ensino, como indicado pelos entrevistados. No final do livro encontra-se uma seção complementar, dentro da qual há sólidos geométricos para serem destacados e utilizados como material de apoio no ensino da geometria, como mostra a imagem a seguir.

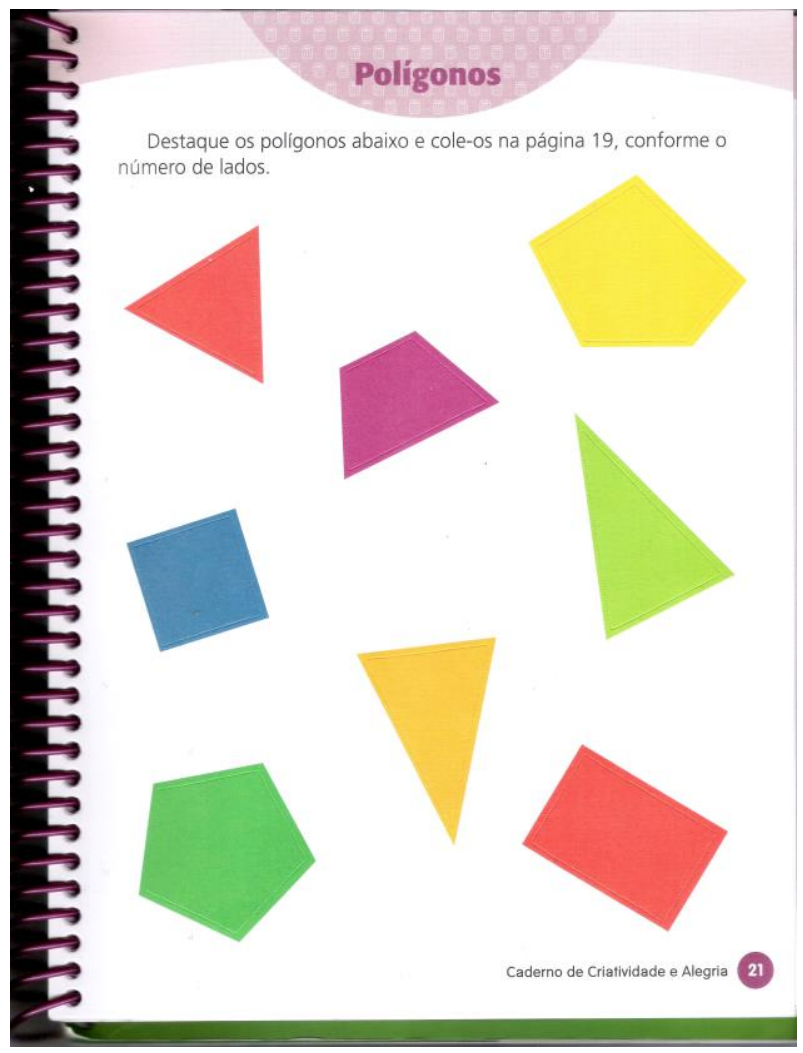

Figura 02: Formas geométricas do livro "Marcha Criança"

Fonte: Teresa et al., 2012

Essa página foi escolhida para ser adaptada como material de apoio magnético para crianças com deficiência visual. Primeiramente, adquiriu-se placa de aço medindo 240x320x3 mm, pesando cerca de 200 gramas.

Para que suas pontas não oferecessem risco aos usuários, revestiu-se o material com E.V.A. de 400x400x2 mm na coloração preta. Com o E.V.A devidamente acertado às dimensões da placa de metal, utilizou-se cola específica, aplicando-se em suas extremidades e aguardando-se um período de 12 horas para fixação completa do material. $\mathrm{O}$ resultado final é demonstrado na figura 03. 


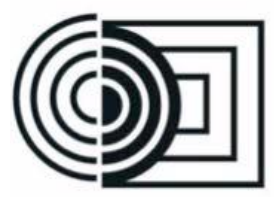

ERGODESIGN USIHC CINAHPA

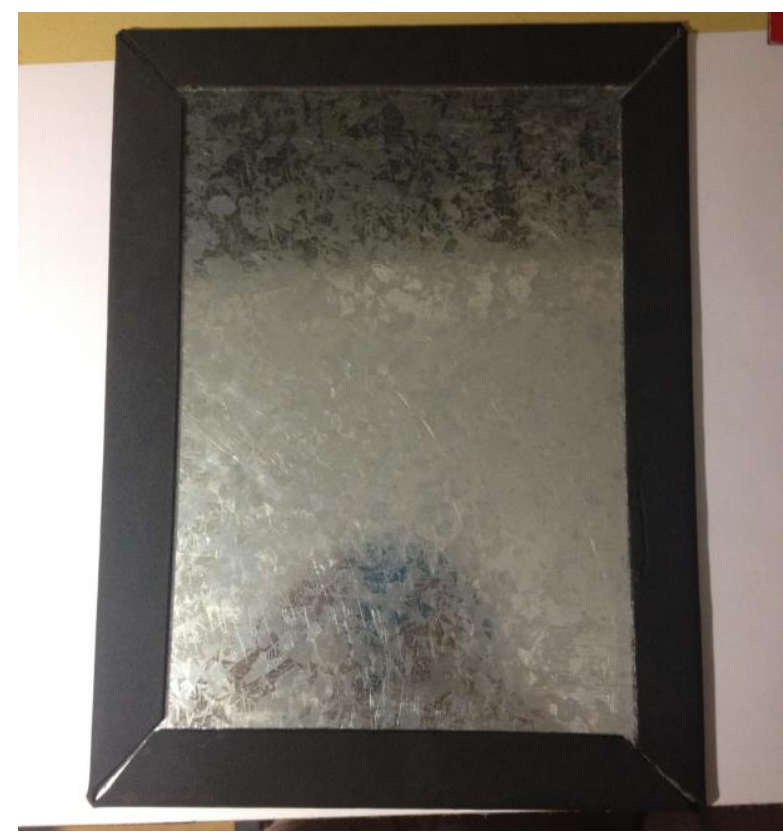

Figura 03: Placa com E.V.A. colado

Fonte: Autoria Própria, 2014

A seguir, foi adquirido ímã flexível de $3 \mathrm{~mm}$ de espessura comprado em um metro por $620 \mathrm{~mm}$ de altura. Então, as formas geométricas a serem fixadas no ímã foram adaptadas e impressas em papel adesivo. Com a utilização da reglete (Figura 04) foram escritos os nomes dos sólidos. Para maior entendimento tátil, as formas reproduzidas foram ampliadas em relação às originais.

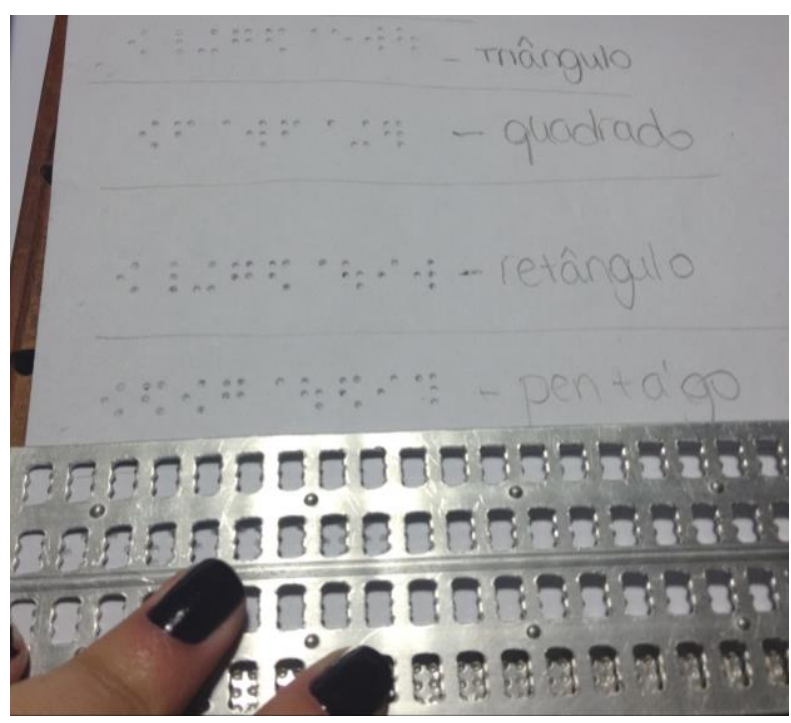

Figura 04: Utilização da reglete

Fonte: Autoria Própria, 2014 $16^{\circ}$ Ergodesign - Congresso Internacional de Ergonomia e Usabilidade de Interfaces Humano Tecnológica: Produto, Informações Ambientes Construídos e Transporte

$16^{\circ}$ USIHC - Congresso Internacional de Ergonomia e Usabilidade de Interfaces Humano Computador

CINAHPA | 2017 - Congresso Internacional de Ambientes Hipermídia para Aprendizagem.
Em seguida, as formas foram fixadas e recortados com tesoura até adquirirem seu formato original (Figura 05).

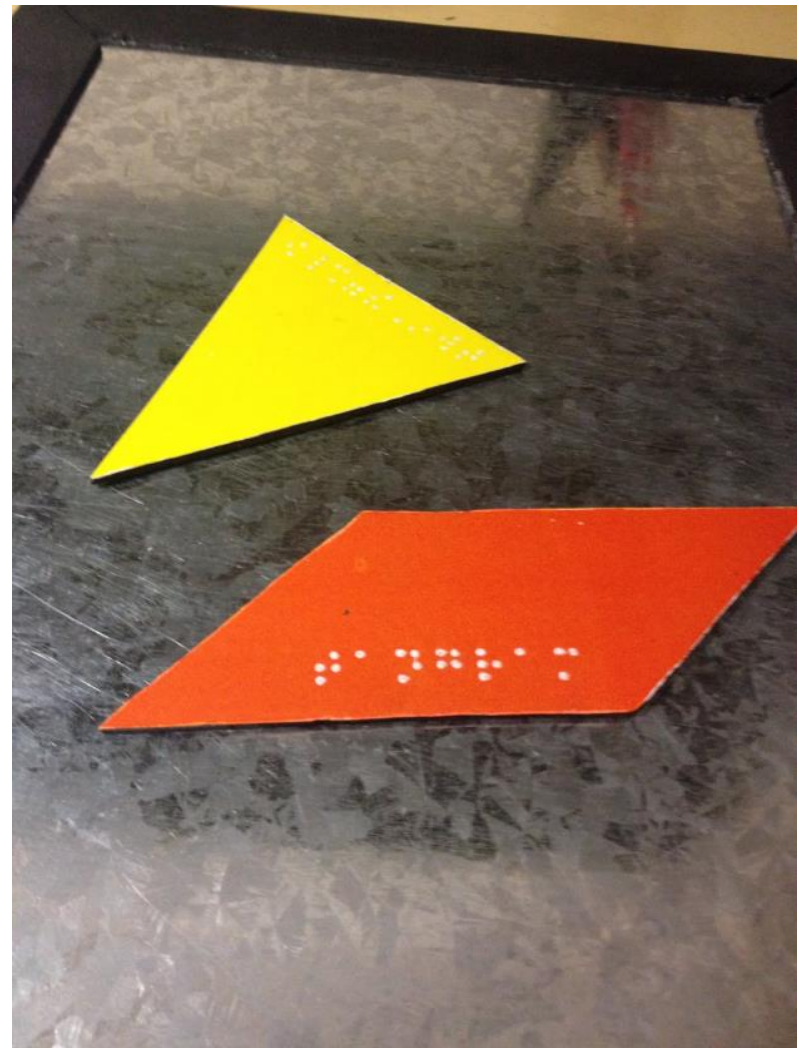

Figura 05: Primeiro resultado dos ímãs com papel adesivo escrito em Braille

Fonte: Autoria Própria, 2014

Como demonstra a figura 04, realizaram-se testes relativos aos tamanhos dos nomes dos sólidos em Braille, para que as dimensões das peças magnéticas comportassem as descrições. Com o objetivo de se ter uma primeira opinião com o público alvo, foi realizada entrevista com um aluno da Escola Municipal Francisco Klemtz (Curitiba-Pr), de seis anos, deficiente visual desde seu nascimento e que cursava o primeiro ano do ensino fundamental. Acompanhando a entrevista também estavam presentes duas professoras responsáveis pela criança, uma delas também deficiente visual.

$\mathrm{O}$ aluno, além de frequentar a escola regular pelas manhãs, também ia ao Instituto Paranaense de Cegos durante o período da tarde, como forma de complementar seus estudos e o inserir no cotidiano de outros colegas com a mesma deficiência. $\mathrm{Na}$
Realização:

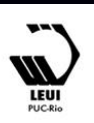




\section{$16^{\circ}$ \\ ERGODESIGN USIHC CINAHPA}

Escola, a criança estava inserida às demais videntes, contando com material de apoio e utilizando com frequência a reglete e a máquina de escrever em Braille. O aluno também demonstrava grande interesse pela disciplina de matemática e lia o Braille com facilidade. Quando apresentado à placa magnética, o aluno primeiramente tateou as bordas em E.V.A., e em seguida sustentou o material com as mãos, indicando aprovação em relação ao formato e peso. A medida que as formas geométricas foram entregues, a criança conseguiu identificar acertadamente suas formas, alterando suas posições dentro da placa de metal e, por vezes unindo duas ou mais peças de forma a compor representações de outros objetos. Por exemplo, unindo o triângulo e o quadrado, o aluno afirmou ter composto um "foguete". Essa dinâmica de se trocar objetos de lugar para formar outros estimula a criatividade e imaginação da criança, e é facilitada pelo material magnético. A professora com deficiência visual que acompanhava o processo, em contato com o material, sugeriu que além das formas geométricas ali representadas, fosse adaptado também o "Tangran", que segundo ela oferece maiores oportunidades de se compor novos objetos.

Em um segundo momento, quando tateando as formas geométricas, o aluno se queixou do relevo Braille contido, utilizado para indicar o nome das peças. Segundo a criança, o relevo estava muito baixo e por vezes ilegível, o que se confirmou pela professora; tal fato se deu devido a gramatura do papel adesivo (180 gramas).

Também foi observada a necessidade do conteúdo em Braille estar impresso em ambos os lados de cada peça, pois a medida que a criança foi tateando e formado o foguete com as formas geométricas, trouxe o verso da peça às suas mãos e não identificou o conteúdo em ambos os lados. Outra entrevista foi realizada com alunos com deficiência visual que frequentam a Sessão Braille da Biblioteca Pública do Paraná, acompanhada pelo coordenador do departamento, também portador de deficiência visual. As crianças igualmente identificaram com facilidade as formas geométricas, por vezes as retirando da placa magnética e colocando-as sobre livros e cadernos, de maneira a formar comparativos com o contexto quais estavam inseridas. $\mathrm{O}$ baixo relevo do Braille $16^{\circ}$ Ergodesign - Congresso Internacional de Ergonomia e Usabilidade de Interfaces Humano Tecnológica: Produto, Informações Ambientes Construídos e Transporte

$16^{\circ}$ USIHC - Congresso Internacional de Ergonomia e Usabilidade de Interfaces Humano Computador

CINAHPA | 2017 - Congresso Internacional de Ambientes Hipermídia para Aprendizagem. também foi criticado, assim como a ausência de identificação das peças em ambos os lados. Acrescentou-se a necessidade de conteúdo em Braille além das peças, como por exemplo na placa de metal ou no E.V.A., afim de se oferecer uma identificação maior ao usuário que entrasse em contato com o material. O acréscimo de outras formas geométricas foi indicado para uma maior abrangência e uso coletivo do material: quanto mais peças, mais possibilidades podem ser imaginadas e formadas.

A partir das opiniões coletadas, foram realizadas as correções no material, iniciando-se com a elaboração do Tangran adaptado, igualmente baseado na seção complementar do livro "Marcha Criança", como demonstrado na figura a seguir.

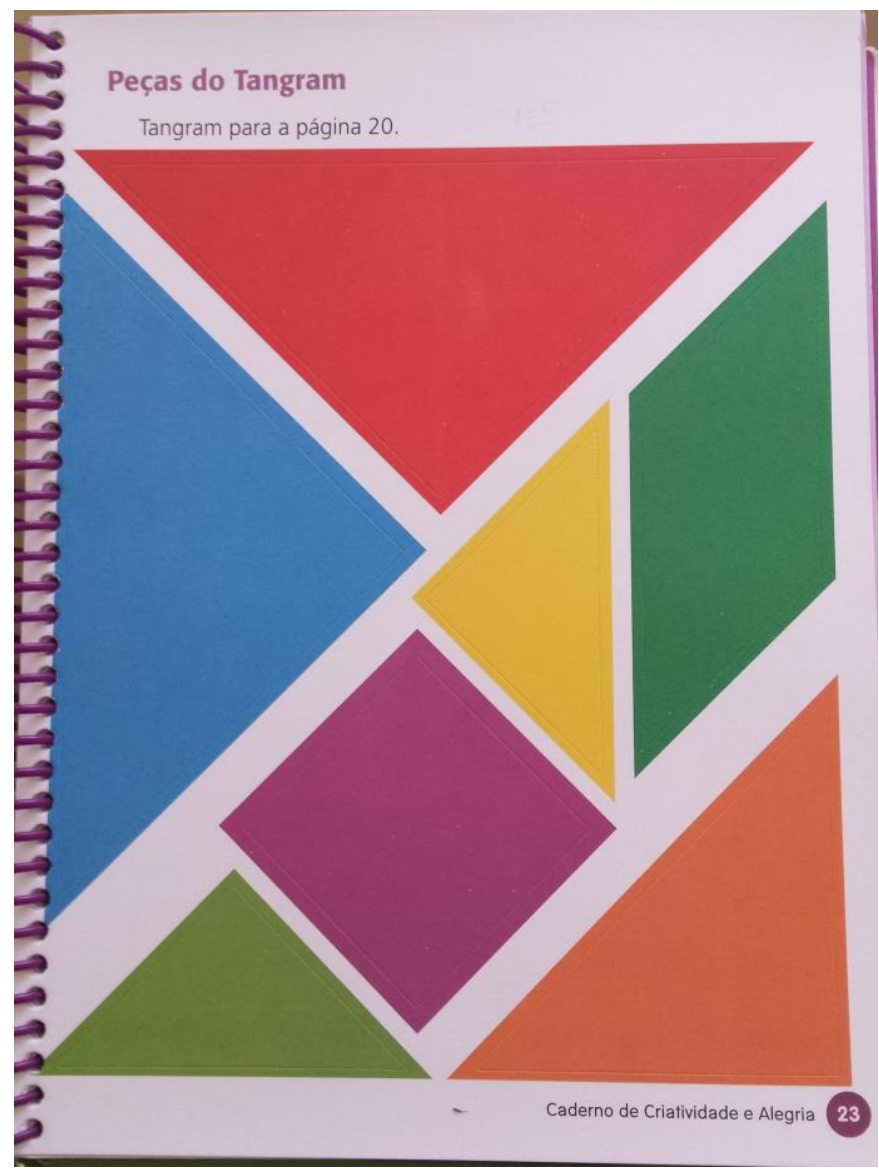

Figura 06: Peças do Tangran do livro "Marcha Criança" Fonte: Teresa et al., 2012

Para a aplicação de um relevo em Braille de maior legibilidade, as peças foram impressas em papel adesivo de gramatura menor, de maneira que o 


\section{$16^{\circ}$ \\ ERGODESIGN USIHC CINAHPA}

$16^{\circ}$ Ergodesign - Congresso Internacional de Ergonomia e Usabilidade de Interfaces Humano Tecnológica: Produto, Informações Ambientes Construídos e Transporte

$16^{\circ}$ USIHC - Congresso Internacional de Ergonomia e Usabilidade de Interfaces Humano Computador

CINAHPA | 2017 - Congresso Internacional de Ambientes Hipermídia para Aprendizagem. conteúdo escrito apresentasse maior evidência no manuseio. Foram inseridas indicações em Braille também na estrutura em E.V.A., igualmente através de papel adesivo.

Para o primeiro volume do livro adaptado do livro "Marcha Criança", estimou-se a adaptação de aproximadamente 50 peças, relativas ao conteúdo da seção complementar do livro. O tamanho destas peças é variado, não ultrapassando $8 \times 8 \mathrm{~mm}$, caso contrário, suas dimensões não seriam adequadas ao tamanho da placa de metal.

Em segundo teste realizado com aluno da Escola Municipal Francisco Klemtz (Curitiba-Pr), aprovaram-se as adaptações, frisando-se a importância de se divulgar o passo a passo da construção do protótipo, de maneira que os professores possam reproduzir o material didático adaptado em suas unidades de ensino.

\section{Discussão}

Para a adaptação impressa de qualquer conteúdo didático para quem não enxerga é necessário rever praticamente tudo, desde o conteúdo até imagens ou gramatura do papel. Com a evolução das tecnologias e meios de impressão, já é possível fornecer materiais em Braille que possuam, além do relevo da escrita, formas que estimulem a imaginação do leitor e o auxiliem numa melhor interpretação do que está sendo lido.

Destaca-se a importância de artifícios táteis implementados fora do livro didático que, através de suas dimensões ajudam o cego a ter noções além do descrito por um texto.

No entanto, na execução do modelo, notou-se a indisponibilidade e falta de recursos para a impressão do mesmo. Com isso, constata-se a dificuldade de acesso a conteúdos em Braille em si: independentemente de serem em grande escala ou não, sua produção ainda se restringe principalmente ao processo manual e a instituições isoladas e pouco divulgadas.

O processo apresentado, realizado de maneira totalmente artesanal, exigiu conhecimentos apurados em relação ao alfabeto Braille e familiarização com o contexto educacional qual as criança estivessem inseridas. Sendo assim, verifica-se que o material de apoio adaptado necessita ser projetado considerando as particularidades de cada grupo de estudantes, exigindo grande habilidade de flexibilização do conteúdo disponibilizado pelos professores. Esses, desempenham papel singular no processo de educação de crianças com deficiência visual, gerenciando e produzindo materiais de apoio, adaptando o espaço no qual o aluno está inserido e verificando suas necessidades e particularidades durante o processo de aprendizagem. A disponibilização de um material de apoio só é eficaz quando sua utilização é devidamente introduzida e explicada pelo educador. A exemplo do material magnético desenvolvido no presente documento, suas possibilidades de uso são diversas, desde que devidamente inseridas e repassadas pelo professor dentro do conteúdo obrigatório da disciplina.

Por fim, firma-se a necessidade em caráter de urgência de maiores investimentos de órgãos públicos, principalmente, no estudo e implementação de novas tecnologias e materiais que facilitem e proporcionem uma diferente experiência educacional para aqueles que não nasceram com o privilégio da visão.

Novos trabalhos que mapeiem a qualidade, testem e desenvolvam novos projetos na área, também se fazem necessários para o desenvolvimento da educação de pessoas com deficiência visual.

\section{Conclusão}

Neste estudo foi possível explorar de maneira satisfatória o desenvolvimento de material de apoio adaptado, alcançando-se um resultado adequado e de boa aceitação de usuabilidade pelos estudantes entrevistados. Destacou-se também a importância do papel do professor no processo, fundamental para o entendimento e utilização adequada do artefato em exercícios repassados em sala de aula. Em relação às metodologias de aprendizagem da criança com deficiência visual, observa-se a importância do desenvolvimento de atividades em grupo, que possibilitem a construção do conhecimento de maneira coletiva, fato que a utilização de diversas peças veio a suprir. Considera-se, para conclusão plena do projeto, o teste com mais alunos, além de orçamento real de uma quantidade suficiente a ser implementada nas escolas. Concomitante aos testes, destaca-se a
Realização:

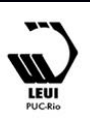




\section{$16^{\circ}$ \\ ERGODESIGN USIHC CINAHPA}

$16^{\circ}$ Ergodesign - Congresso Internacional de Ergonomia e Usabilidade de Interfaces Humano Tecnológica: Produto, Informações Ambientes Construídos e Transporte

$16^{\circ}$ USIHC - Congresso Internacional de Ergonomia e Usabilidade de Interfaces Humano Computador

CINAHPA | 2017 - Congresso Internacional de Ambientes Hipermídia para Aprendizagem. exploração de novos materiais para produção do protótipo. Também leva-se em conta a necessidade de novas testagens do exemplar elaborado junto a mais estudantes do público-alvo em questão e professores, para que novas conclusões e apontamentos sejam levantados, melhorando assim a percepção do produto final. Verifica-se também a necessidade de elaboração de um guia que possibilite a reprodução do projeto por qualquer professor da rede de ensino.

Por fim, também se faz necessária a revisão de todo o material adaptado através de profissional com deficiência visual, afim de detectar possíveis erros de tradução ocorridos no processo e proporcionando assim máxima fidelidade em relação ao conteúdo original.

\section{BIBLIOGRAFIA}

ADAM, Dominique Leite. Adaptação inclusiva do livro infantil the black book of colors. 2011. 98 f. Trabalho de Conclusão de Curso (Bacharelado em Design Gráfico) - Universidade Federal do Paraná, Curitiba, 2011.

AZEVEDO, Alexandre César. Utilizando material didático adaptado para deficientes visuais.

Dissertação (Mestrado Profissional em Ensino de Física) - Universidade Federal do Rio de Janeiro, Rio de Janeiro, 2012.

BAPTISTA, José António Lages Salgado. A Invenção do Braille e a sua Importância na Vida dos Cegos. Lisboa: Gráfica 2000, 2000.

BRITO, Patrícia Ribeiro; VEITZMAN, Sílvia. Causas da cegueira e baixa visão em crianças. Arquivo Brasileiro de Oftalmologia. São Paulo, v.1, n.63, p.49-54, 2000.

DIAS, Elizabet; CAMPOS, Izilda Maria de. Atendimento Educacional Especializado Deficiência Visual. Brasília: Ministério da Educação, 2007.

FLICK, Uwe. Introdução à pesquisa qualitativa. 3.ed. Porto Alegre: Artemed, 2009.

GIL, Marta. Deficiência Visual. Brasília: MEC. Secretaria de Educação a Distância, 2000.
GOMES, Wanda. Inclusão social do deficiente visual a partir de técnicas e processos de impressão em papel. Projeto de design gráfico de livro infantil. In: Anais do congresso brasileiro de pesquisa e desenvolvimento em design, 8., 2008, São Paulo. P. 3863.

LOPES, Sirlei. Insituto Paranaense de Cegos. Entrevista proferida a autora em 10 de abril de 2013.

OLIVEIRA, Tory. Longe do alcance das mãos. Carta Capital, 16 abr. 2011. Disponívelem: < http://www.cartacapital.com.br >. Acesso em: 10 abr. 2013.

PEREIRA, Fernando Marques. A deficiência visual no ensino regular. Disponível em: <http://www.ipv.pt/millenium/Millenium28/8.htm> . Acesso em: 11 abr. 2013.

SOCIEDADE Bíblica do Brasil. A bíblia para pessoas com deficiência visual. Disponível em: <http:// www.sbb.org.br/interna.asp?areaID=143>. Acesso em: 24 set. 2013.

SOUZA, Keli Cristina; GREGAREK. Kellyn Cristina C. Projeto de pesquisa e desenvolvimento de materiais gráficos destinados aos cegos. 2005. $76 \mathrm{f}$. Trabalho de diplomação (Tecnologia em Artes Gráficas) Centro Federal de Educação Tecnológica do Paraná. 2005.

TERESA, Maria et al. Marcha Criança Matemática. São Paulo: Scipicione, 2012.

\section{Agradecimentos}

Agradecemos primeiramente a CAPES (Coordenação de Aperfeiçoamento de Pessoal de Nível Superior) pelo apoio dedicado.

A realização deste trabalho só foi possível devido principalmente ao apoio da Universidade Tecnológica Federal do Paraná, em especial a PróReitoria de Graduação e Educação Profissional, a qual proporcionou, dentro do Programa de Bolsas de Fomento às Ações de Graduação, fundo
Realização:

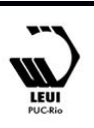




\section{$16^{\circ}$ \\ ERGODESIGN USIHC CINAHPA}

$16^{\circ}$ Ergodesign - Congresso Internacional de Ergonomia e Usabilidade de Interfaces Humano Tecnológica: Produto, Informações Ambientes Construídos e Transporte

$16^{\circ}$ USIHC - Congresso Internacional de Ergonomia e Usabilidade de Interfaces Humano Computador

CINAHPA | 2017 - Congresso Internacional de Ambientes Hipermídia para Aprendizagem.

monetário para a realização do modelo aqui proposto.

Agradeçemos a equipe do Instituto Paranaense de Cegos do Paraná por despender seus profissionais para entrevistas e a seção braille da Biblioteca Pública do Paraná, pela disponibilidade e assistência em consulta a seu acervo e estudantes que frequentam o espaço.

Agradeçemos também a Escola Municipal Francisco Klemtz pela disponibilização de suas professoras, as quais, através de suas experiências e opiniões, transformaram o presente trabalho. Também manifestamos nossa profunda gratidão a D.N.C de seis anos que, com seu carisma e inteligência, contribuiu muito para o desenvolvimento do presente projeto. 